\title{
Heavy Metal Tolerance of Fungi Isolated from Contaminated Soil
}

\author{
Jin Ho Joo* and Khalid A. Hussein \\ Department of Biological Environment, Kangwon National University, 192-1 Hyo-Ja Dong, Chuncheon, \\ Kangwon-do 200-701, South Korea
}

\begin{abstract}
This study was conducted to investigate the tolerance of some resistant fungal strains from soils contaminated with heavy metals. Various fungal strains were isolated from soil samples collected from studied sites which heavy metals and other pollutants have been emitted in effluents for several years. Fungi isolated belong to different genera; however, Penicillium spp. showed the most frequent species. The microbial number was remarkably higher in the control soil than contaminated soil samples collected from mining areas. $\mathrm{Pb}^{2+}$ and $\mathrm{Zn}^{2+}$ had the highest concentration in the polluted soils ranging from $89-3,521 \mathrm{ppm}$ and $98-4,383 \mathrm{ppm}$, respectively. The minimum inhibition concentrations (MICs) of $\mathrm{Pb}^{+2}$ and $\mathrm{Zn}^{+2}$ showed the highest values against the fungal strains. $\mathrm{Ni}^{+2}$ and $\mathrm{Co}^{+2}$ were the lowest contaminants in the polluted soils with the concentration of 5 to $12.1 \mathrm{ppm}$ and 1.8 to $4.8 \mathrm{ppm}$, respectively. The tested resistant strains showed the strongest inhibition for $\mathrm{Ni}^{+2}$ and $\mathrm{Co}^{+2}$ up to 200-400 ppm. Cadmium was the most highly toxic heavy metal for most of strains, however, $1 \mathrm{mM}$ of $\mathrm{Cr}^{3+}, \mathrm{Cu}^{2+}$ and $\mathrm{Pb}^{2+}$ accelerated the growth of Penicillium verrucosum KNU3. $\mathrm{Cu}^{+2}$ and $\mathrm{Zn}^{+2}$ at concentration of $1 \mathrm{mM}$ did not affect the growth rate $P$. funiculosum KNU4. Tolerance of fungal species to heavy metals appears to be strain and origin dependent.
\end{abstract}

Key words: Heavy metals, Fungi, Minimum inhibition concentration, Resistance

\section{Introduction}

It has been shown that heavy metals at certain concentrations can have long-term toxic effects within ecosystems and have a clear negative influence on biologically mediated soil processes (Lee et al., 2002). Heavy metal release to the environment has been increased recently because of industrial activities and technological development and causes serious problem to the environment, soil, and water resources. Due to their high occurrence as contaminants, heavy metals have a great concern to environmental issues present in soluble form that are very toxic to biological systems, moreover, the classification of several heavy metals as carcinogenic and mutagenic (Alloway, 1995; Diels et al., 2002). Fungi are known to tolerate and detoxify metals by several mechanisms including valence transformation, extra and intracellular precipitation and active uptake (Gadd, 1993). Therefore, it is expected that screening of metal tolerant fungi may provide strains with improved metal accumulation. It is generally assumed that microorganisms concentrate accumulated metals in the cell surface. Such phenomenon

\footnotetext{
Received : 2012. 7. 10 Accepted : 2012. 8. 4

*Corresponding author : Phone: +823332506448

E-mail: jhjoo@kangwon.ac.kr
}

results from complexation and/or ion exchange reactions between metal ions and the charged chemical constituents of cell walls (Gupta et al., 2000). Generally, the contaminated sites are the sources of metal resistant micro-organisms (Gadd, 1993). Filamentous fungi and yeasts can also show high levels of metals and metalloids resistance, being this resistance associated to the capacity to accumulate these elements (Cánovas et al., 2003; Durán et al., 1999; Itoh et al., 1998 , Silóniz et al., 2002). Fungi and yeast biomasses are known to tolerate heavy metals (Gavrilesca, 2004; Baldrian, 2003). Davis et al. (2002) showed that long-term exposure to $\mathrm{Zn}$ imposes stress on soil microbes, resulting in an increased tolerance. They concluded that the long-term accumulation of $\mathrm{Zn}$ in soils provides the microbial community with time to adapt to this metal. Indeed, microbial communities are often found to recover after an initial inhibition by high metal inputs (Holtan Hartwik et al., 2002). Therefore, the soil microbial community is thought to be a sensitive bioindicator of metal pollution effects on bioavailability and biogeochemical processes (Hinojosa et al., 2005). It is generally accepted that accumulation of heavy metals in soil reduces the amount of soil microbial biomass (Chander et al., 1995).

The objective of this study is to isolate fungal strains resistant to heavy metals from contaminated soils and to 
investigate the tolerance index of stressed strains through the minimum inhibition concentration (MIC).

\section{Materials and methods}

Soils physical and chemical properties Four soil samples were collected from different mining areas in clean zipper bags and ice box and directly transferred to laboratory for physicochemical properties analyses. The fifth soil sample was collected from agriculture area. The soil $\mathrm{pH}$ and $\mathrm{EC}$ of 1:5 (soil and water mixtures) were determined using a $\mathrm{pH}$ meter (Orion 3 Star, Thermo, USA). The exchangeable cations were analyzed by inductively coupled plasma (ICP) spectrometry after $1 \mathrm{M}$ $\mathrm{NH}_{4} \mathrm{OAc}$ extraction (Sumner and Miller 1996). Soil samples were air-dried and shaken through a 2-mm sieve. The total concentration of heavy metals was estimated by digestion in $10-\mathrm{mL} 60 \% \mathrm{HNO}_{3}$ and microwave oven-drying at $200 \pm 5^{\circ} \mathrm{C}$ for $20 \mathrm{~min}$ (Mars-X, HP-500 plus, CEM Corp.) according to EPA Method 3051 (USEPA, 1994). The concentrations of $\mathrm{Co}, \mathrm{Cr}, \mathrm{Cu}, \mathrm{Fe}, \mathrm{Ni}, \mathrm{Pb}$, and $\mathrm{Zn}$ were determined by inductively coupled plasma/ atomic emission spectroscopy (ICP-AES; Perkin Elmer Optima, USA).

Fungi and growth conditions Several fungi belonging to different classes were isolated on Czapek's solution Agar containing saccharose $30 \mathrm{~g}$; sodium nitrate $2 \mathrm{~g}$; Dipotassium phosphate $1 \mathrm{~g}$; magnesium sulfate $0.5 \mathrm{~g}$; potassium chloride $0.5 \mathrm{~g}$; ferrous sulfate $0.01 \mathrm{~g}$; Agar $15 \mathrm{~g}$. Stock cultures of fungi were maintained on $2 \%$ malt extract-agar (MEA) plates grown at $27^{\circ} \mathrm{C}$, except to and stored at $5^{\circ} \mathrm{C}$.

Identification of isolates Most of fungal strains were identified by the microscopic examination and the culture features according to Domsch et al. (1980) and Moubasher (1993). The isolated DNA was then used as a template for PCR to amplify the 18S rRNA gene. A universal fungal primer set of 27F (5'-AGA GTT TGA TCC TGG CTC AG- $\left.3^{\prime}\right)$ and 1492R (5'-GGTTAC CTT GTT ACG ACT T- $3^{\prime}$ ) was used to amplify the nearly complete $18 \mathrm{~S}$ rRNA gene. The partial 18S rRNA gene sequence was compared with the full sequence available in the GenBank database using a BLAST search (NCBI) to identify of the isolated fungi.

Determination of minimum inhibitory concentrations (MICs) The resistance of the selected isolates to heavy metals was determined by the dilution method. Metal ions were added separately to PDA medium at concentrations of 100 to $1,000 \mathrm{ppm}$. The plates were inoculated with 5 $\mathrm{mm}$ agar block from young fungal colonies, pre-grown on PDA. Three replicates of each concentration and controls without metal were used. The inoculated plates were incubated at $25^{\circ} \mathrm{C}$ for at least 7 days. The minimum inhibitory concentration (MIC) is defined as the lowest concentration of metal that inhibit visible growth of the isolate.

\section{Investigation for the heavy metals tolerance index of} fungi Under aseptic conditions PDA plates supplemented with $1 \mathrm{mM}$ of the heavy metals were inoculated with a disc of mycelia. The cultures were incubated at 2 $7^{\circ} \mathrm{C}$ for 7 days, the diameter of the cultures were measured and compared with control culture diameter to calculate the tolerance index (TI). TI is defined as the ratio of the diameter of the treated colony to that of the untreated colony of the same fungal isolate.

\section{Results and Discussion}

The physicochemical properties of soil samples The $\mathrm{pHs}$ of the contaminated soil ranged from 4.7-8.1, while it was 6.7 in the control soil. The electric conductivity measured in the polluted soils was ranged from 0.1-1.3 dS $\mathrm{m}^{-1}$; however it was $0.14 \mathrm{dS} \mathrm{m}^{-1}$ in the control soil. The amount of $\mathrm{NH}_{4}-\mathrm{N}$ ranged $11.3-35.8 \mathrm{mg} \mathrm{kg}^{-1}$; while it was $14.9 \mathrm{mg} \mathrm{kg}^{-1}$ in the control soil. The amount of $\mathrm{NO}_{3}-\mathrm{N}$ ranged 1.1-6.2 $\mathrm{mg} \mathrm{kg}^{-1}$; while it was $7.1 \mathrm{mg} \mathrm{kg}^{-1}$ in the control one Table 1.

Heavy metals concentrations It was observed that $\mathrm{Pb}^{2+}$ and $\mathrm{Zn}^{2+}$ had the highest concentration in the polluted soils ranging from 89 - 3,521 ppm and 98 - 4,383 ppm, respectively. However, $\mathrm{Ni}^{2+}$ and $\mathrm{Co}^{2+}$ showed lower levels ranging from 5-12.1 and 3.5-4.8 ppm (Table 2). It is well known that a long-term exposure of water and soil to heavy metals can produce considerable modification of their microbial populations, reducing their activity and their number (Doelman et al., 1994). Heavy metal resistant microorganisms play an important role in the bioremediation of heavy metal contaminated soils (Ray and Ray 2009; Abou-Shanab, et al. 2007). In the present study, various fungal strains were isolated from soil samples collected from studied sites which heavy metals and other 
Table 1.The physicochemical properties and the microbial density of the studied soils.

\begin{tabular}{|c|c|c|c|c|c|c|c|c|c|c|c|}
\hline \multirow{3}{*}{ No. } & \multirow{2}{*}{ Site } & \multirow{2}{*}{$\mathrm{pH}$} & \multirow{2}{*}{$\mathrm{EC}^{\ddagger}$} & \multirow{2}{*}{$\mathrm{NH}_{4}-\mathrm{N}$} & \multirow{2}{*}{$\mathrm{NO}_{3}-\mathrm{N}$} & \multicolumn{4}{|c|}{ Exchangeable cations } & \multirow{2}{*}{\multicolumn{2}{|c|}{$\begin{array}{l}\text { Microbial density } \\
\mathrm{CFU} \mathrm{g}{ }^{-1} \text { soil } \times 10^{4}\end{array}$}} \\
\hline & & & & & & $\mathrm{Ca}^{2+}$ & $\mathrm{Mg}^{2+}$ & $\mathrm{K}^{+}$ & $\mathrm{Na}^{+}$ & & \\
\hline & & & $\mathrm{dS} \mathrm{m}^{-1}$ & \multicolumn{2}{|c|}{$\mathrm{mg} \mathrm{kg}^{-1}$} & $\begin{array}{ll}----- \\
--\end{array}$ & $-\mathrm{cmc}$ & $\mathrm{kg}^{-1}-$ & ------ & Bacteria & Fungi \\
\hline 1 & Baeknyeon mine & 4.7 & 1.30 & 11.38 & 6.21 & 6.10 & 0.40 & 0.12 & 0.07 & 2 & 6 \\
\hline 2 & Jucheon mine & 8.0 & 0.20 & 15.75 & 1.14 & 29.88 & 1.65 & 0.03 & 0.03 & 133 & 0.1 \\
\hline 3 & Hanheung mine & 8.1 & 0.23 & 21.88 & 5.86 & 51.04 & 0.79 & 1.04 & 0.07 & 25 & 0.1 \\
\hline 4 & Bongwha mine & 6.1 & 0.10 & 35.88 & 1.66 & 14.23 & 4.51 & 0.56 & 0.06 & 2 & 45 \\
\hline 5 & Agricultural soil & 6.7 & 0.14 & 14.88 & 7.10 & 10.94 & 1.23 & 0.44 & 0.34 & 2100.00 & 70.00 \\
\hline
\end{tabular}

${ }^{\dagger}$ Organic matter, ${ }^{\ddagger}$ electrical conductivity, ${ }^{\S}$ total carbon, " total nitrogen.

Table 2. ICP heavy metals content of the contaminated sites and the control soil (mg/kg).

\begin{tabular}{|c|c|c|c|c|c|c|c|c|c|}
\hline No. & Site & $\mathrm{Cd}$ & $\mathrm{Pb}$ & $\mathrm{Cr}$ & $\mathrm{Ni}$ & $\mathrm{Cu}$ & $\mathrm{Zn}$ & Co & $\mathrm{Fe}$ \\
\hline 1 & Baeknyeon mine & 3.8 & 348.6 & 8.5 & 5 & 122.6 & 143.1 & 1.8 & 13315.6 \\
\hline 2 & Jucheon mine & 67.3 & 3521.4 & 13.5 & 12.1 & 265.4 & 4383 & 4.8 & 36950.6 \\
\hline 3 & Hanheung mine & 2.3 & 89.8 & 14.2 & 8.3 & 76.5 & 98.6 & 3.5 & 12214.3 \\
\hline 4 & Bongwha mine & 3.9 & 1230.7 & 10.2 & 5.1 & 105.1 & 529.5 & 4.7 & 17714.6 \\
\hline 5 & Control (Agriculture soil) & 1.7 & 42 & 8.8 & 4.4 & 14 & 104.8 & 2.5 & 11926.3 \\
\hline
\end{tabular}

Table 3. MIC for the most resistant fungal strains on Potato Dextrose broth medium.

\begin{tabular}{lccccccc}
\hline \hline \multirow{2}{*}{ Fungal species } & \multicolumn{7}{c}{ Heavy metals (ppm) } \\
\cline { 2 - 8 } & $\mathrm{Cd}^{2+}$ & $\mathrm{Co}^{2+}$ & $\mathrm{Cr}^{3+}$ & $\mathrm{Cu}^{2+}$ & $\mathrm{Ni}^{2+}$ & $\mathrm{Pb}^{2+}$ & $\mathrm{Zn}^{2+}$ \\
\hline Penicillium notatum KNU1 S1 & 500 & 400 & 500 & 400 & 400 & 800 & 800 \\
Saccharomyces serviciae K2 S2 & 500 & 400 & 500 & 300 & 300 & 700 & 800 \\
Rhodosporidium toruloides M1 S2 & 500 & 400 & 500 & 500 & 400 & 700 & 700 \\
Aspergillus niger KH3 S3 & 500 & 400 & 800 & 500 & 400 & 800 & 800 \\
Penicillium verrucosum KNU3 S3 & 400 & 400 & 400 & 400 & 400 & 700 & 700 \\
Pencillium funiculosum KNU4 S4 & 500 & 400 & 800 & 400 & 400 & 800 & 800 \\
Penicillium glabrum KNU5 S5 & 200 & 200 & 300 & 100 & 200 & 500 & 500 \\
\hline MiC: concen
\end{tabular}

MIC: concentration at which no growth was occurred.

pollutants have been emitted in industrial effluents for several years. Fungi isolated belong to different genera; however, Penicillii appeared the most frequent species (Table 3).

The microbial density The highest microbial number was counted in the control sample; however, there was remarkable difference of the fungal occurrence in the collected polluted samples (Table 1). For example, in area No.1 (Baeknyeon mining area) the number of fungi was $6 \times 10^{4} \mathrm{CFU} \mathrm{g}^{-1}$ soil. While in the control (unpolluted soil) the account of fungi was $70 \times 10^{4} \mathrm{CFU} \mathrm{g}^{-1}$ soil. Heavy metals were reported to inhibit the fungal growth. It is generally accepted that accumulation of HMs in soil reduces the amount of soil microbial biomass (Chander et al., 1995). It was indicated by a prolongation of growth rate, log period, lag period and generation time (Mahapatra and Banerjee 1996). Although metals may induce changes in the microbial community resulting in microorganisms more resistant to metals (Almås et al., 2004), most essential and non essential metals exhibit toxicity above a certain concentration.

Strains identification Genetic analysis was tried to confirm the microscopic identification of our isolates. The 18S r-RNA analysis was followed by blast search via National Center for Biotechnology Information (NCBI) database and the sequence was compared to other available $18 \mathrm{~S}$ r-RNA sequences, and the results were in conformity agreement not less than $99 \%$ for such colony characterizations. Such as, the $18 \mathrm{~S}$ r-RNA analysis showed that isolate $P$. notatum KNU1 had 99\% nucleotide base 
homology with $P$. notatum, A. niger KNU3 had 99\% homology with $A$. niger var. niger, Rhodosporidium toruloides M1 had 99\% homology with had 99\% homology with Rhodosporidium toruloides.

Determination of the MIC We selected the most potent species to carry out MIC and Tolerance index measurement of the resistant strains (Table 3, 4). The MIC of the potent fungal species ranged from $400-800 \mathrm{ppm}$ for all heavy metals except non-resistant Penicillium glabrum isolated from control soil. MICs of the most resistant isolates against the seven tested metals ions are shown in Table 3 in comparing with non-resistant strain isolated from control soil. The growth rate of the resistant isolates seems to be adapted with the high concentrations of metal ions. Fig. 1 shows the variation in toxicity among different heavy metals, $\mathrm{Co}^{2+}$ and $\mathrm{Ni}^{2+}$ seem to be the most toxic metal ion, however, $\mathrm{Zn}^{2+}$ and $\mathrm{Pb}^{2+}$ were the lowest in toxicity (Fig. 2). That may be due to the role of $\mathrm{Zn}^{2+}$ and $\mathrm{Pb}^{2+}$ in the fungal metabolism. Zinc is essential element for all organisms, although at high concentrations it can be toxic (Balsalobre et al., 2003). Ezzouhri et al. (2009) reported that lead ions appeared less toxic in comparison with the others metals studied and weakly inhibited of growth of Alternaria alternata. Table 3 shows all metals, whether essential and non essential tend to show toxicity at certain levels. MIC may be presented differently, depending on the fungal species and its site characterization. For example, the $\mathrm{MIC}$ of $\mathrm{Cr}^{+3}$ for Aspergillus niger KNU3 and Penicillium funiculosum KNU4 was 800ppm for each, while the other tolerant species e.g. Penicillium sp. and yeasts recorded MICs in the range 300-500 ppm of the same heavy metal. It is worthy to mention that the lowest MICs for the resistant fungal species were found in $\mathrm{Ni}^{+2}$ stresses, that may due to its low concentration originally in the contaminated soil samples. Also, $\mathrm{Co}^{+2}$ presented low values of MICs against the tested resistant isolates, which was $400 \mathrm{ppm}$ for all tested species except P. glabrum that was isolated from the control soil. Table 2 shows that the $\mathrm{Ni}^{+2}$ and $\mathrm{Co}^{+2}$ were the lowest contaminants in the polluted soils which have 5 to $12.1 \mathrm{ppm}$ and 1.8 to 4.8ppm, respectively. Malik (2004) found that the strains
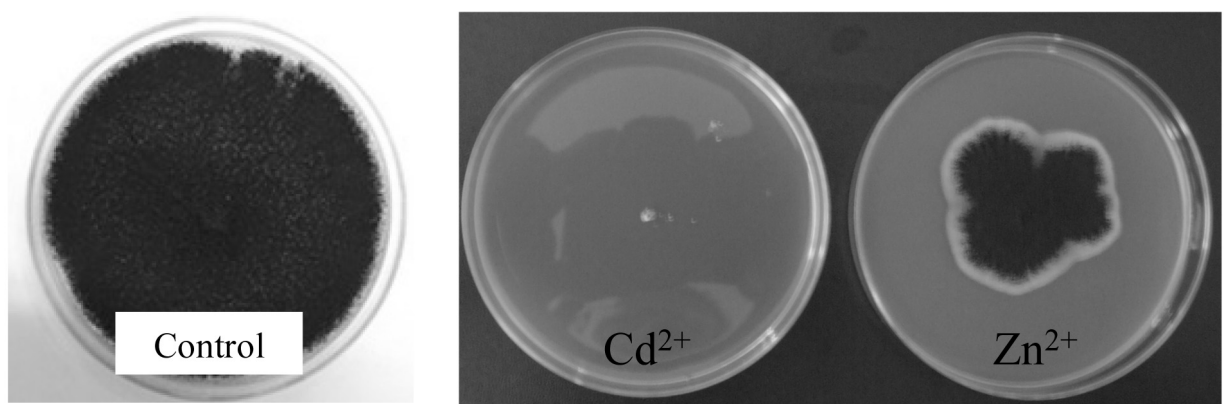

Fig. 1. Effect of $1 \mathrm{mM}$ of $\mathrm{Cd}^{+2}$ and $\mathrm{Zn}^{+2}$, Non-essential and essential heavy metals, respectively, on the growth of Aspergillus niger KNU3 as resistant fungal strain.

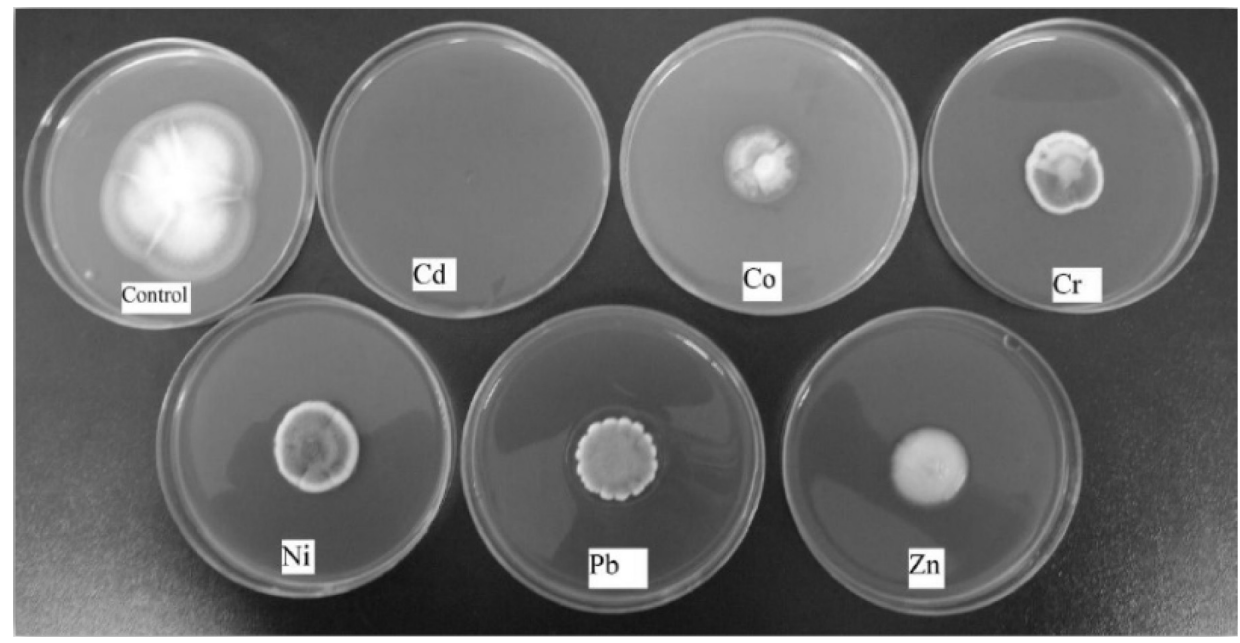

Fig. 2. Tolerance index of $1 \mathrm{mM}$ of different heavy metals on the growth of Penicillium notatum KNU1 as a resistant fungal strains. 
Table 4. Tolerance index (TI) of isolated fungi able to grow on PDA amended with $1 \mathrm{mM}$ of metal.

\begin{tabular}{lccccccc}
\hline \hline \multirow{2}{*}{ Fungal isolates and sites } & \multicolumn{7}{c}{ Heavy metals } \\
\cline { 2 - 8 } & $\mathrm{Cd}^{2+}$ & $\mathrm{Co}^{2+}$ & $\mathrm{Cr}^{3+}$ & $\mathrm{Cu}^{2+}$ & $\mathrm{Ni}^{2+}$ & $\mathrm{Pb}^{2+}$ & $\mathrm{Zn}^{2+}$ \\
\hline Penicillium notatum KNU1 S1 & 0 & 0.66 & 0.73 & 0.8 & 0.73 & 0.73 & 0.73 \\
Botrytis aclada Kh2 S2 & 0 & 0.33 & 0.52 & 0.57 & 0.9 & 0.76 & 0.66 \\
Penicillium verrucosum KNU3 S3 & 0.13 & 0.76 & 1.08 & 1.08 & 0.87 & 1.04 & 1 \\
Aspergillus niger KH3 S3 & 0 & 0.85 & 0.6 & 0.64 & 0.66 & 0.74 & 0.71 \\
Pencillium funiculosum KNU4 S4 & 0 & 0.85 & 0.6 & 0.64 & 0.66 & 0.71 & 0.71 \\
Penicillium glabrum KNU5 S5 & 0 & 0.9 & 1.1 & 1 & 1.2 & 0.9 & 1 \\
\hline
\end{tabular}

(TI): The ratio of colony diameter grown on media containing $1 \mathrm{mM}$ of the heavy metal to the colony diameter in control

isolated from contaminated soil are more tolerant to heavy metals stress. Indeed, microbial communities are often found to recover after an initial inhibition by high metal inputs (Holtan-Hartwik et al., 2002). Generally, the contaminated sites are the sources of metal resistant micro-organisms (Gadd, 1993).

The tolerance index of fungi Heavy metal resistance was limited according growth inhibition by $1 \mathrm{mM} \mathrm{Cd}$, Co, $\mathrm{Cr}, \mathrm{Cu}, \mathrm{Pb}, \mathrm{Ni}$, and $\mathrm{Zn}$ (Nakahara et al. 1978). The most toxic heavy metals in this test were $\mathrm{Cd}^{2+}$ followed by $\mathrm{Co}^{2+}$ (Table 4). The ratio of colony diameter grown on media containing $1 \mathrm{mM}$ of the heavy metal to the colony diameter in control was known as the tolerance index of fungi (TI). The value of (TI) of the heavy metal resistant fungal species usually is below one, however, some heavy metals showed some increase in this value e.g. $\mathrm{Cr}^{3+}$ and $\mathrm{Cu}^{2+}$ in the case of both Penicillium verrucosum KNU3 and P. funiculosum KNU4, that implies some heavy metals in certain dose may increase the growth of the resistant species (Table 4) and (Fig. 3, 4). $1 \mathrm{mM} \mathrm{of} \mathrm{Cr}^{+3}$ and $\mathrm{Ni}^{+2}$ enhanced the growth of $P$. funiculosum $\mathrm{KNU} 4$ as a resistant fungal strains. However, $\mathrm{Cd}^{+2}$ suppressed the growth completely. Similarly, Levinskaite (2002), studying the response of soil fungi to hexavalent chromium, reported that Trichoderma viride and $P$. chrysogenum are the most tolerant fungi to the presence of $2 \mathrm{mM}$ chromium in the medium Isolates from the genus. This toxicity stress, appreciated by a threshold value (Leyval and Joner, 2001). Table 4 shows that isolates of the same genus could record marked difference in tolerance of heavy metals. 1 $\mathrm{mM}$ of $\mathrm{Cu}^{+2}$ and $\mathrm{Cr}^{+3}$ activated the growth of $P$. verrucosum $\mathrm{KNU} 3$, however, the same concentration declined the colony diameter of $P$. notatum KNU1. $1 \mathrm{mM}$ of $\mathrm{Cr}^{+3}$ slightly activated the growth of $P$. funiculosum $\mathrm{KNU} 4$, while $\mathrm{Cu}^{+2}$ did not show effect on the same

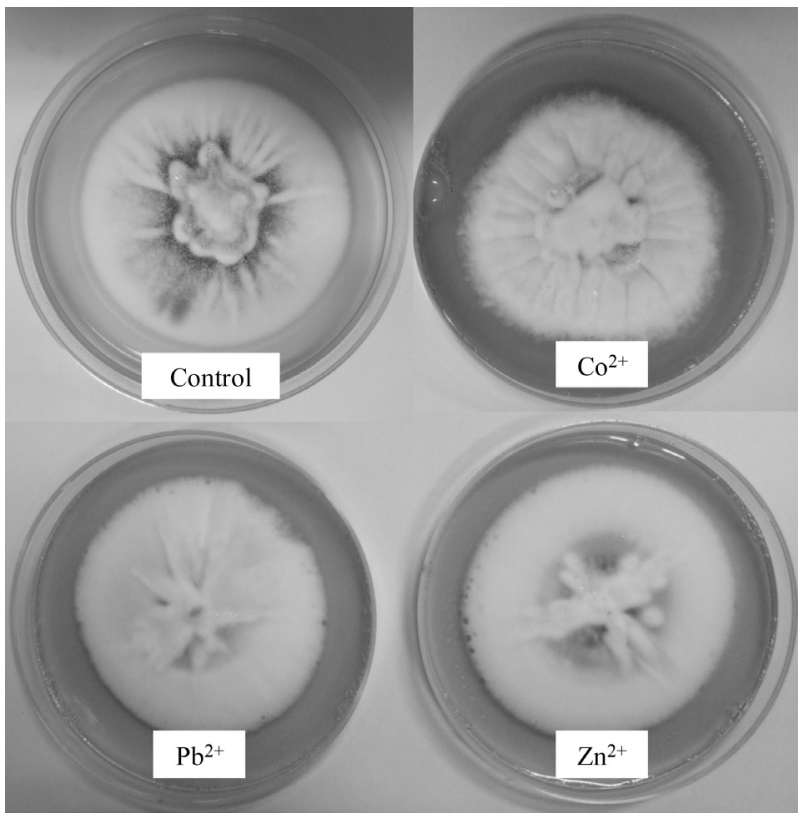

Fig. 3. The tolerance index of $1 \mathrm{mM}$ of different heavy metals, $\mathrm{Co}^{+2}$ and $\mathrm{Pb}^{+2}$ decrease the growth slightly of $\boldsymbol{P}$. funiculosum KNU4 as a resistant fungal strains, while $\mathrm{Zn}^{2+}$ has no effect.

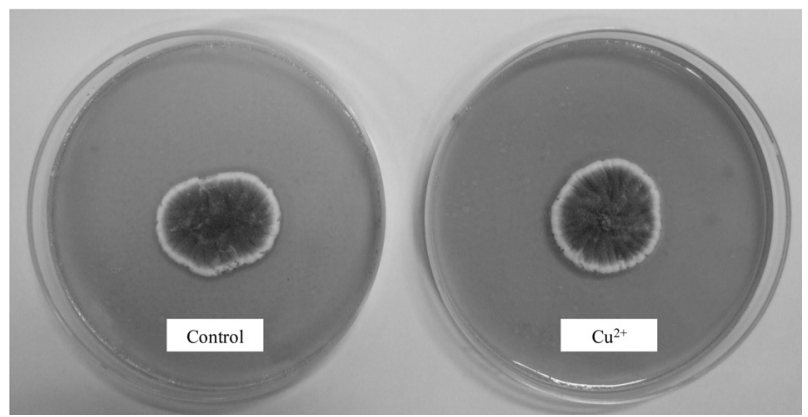

Fig. 4. The tolerance index of $1 \mathrm{mM}$ of $\mathrm{Cu}^{+2}$ enhancing the growth of $P$. verrucosum KNU3 as a resistant fungal strains.

resistant isolate. The growth rate of $P$. glabrum that was isolated from uncontaminated soil was decreased by all heavy metals (Fig. 5). Also, all the seven heavy metals declined the growth rate of the resistant isolate of $A$. niger 


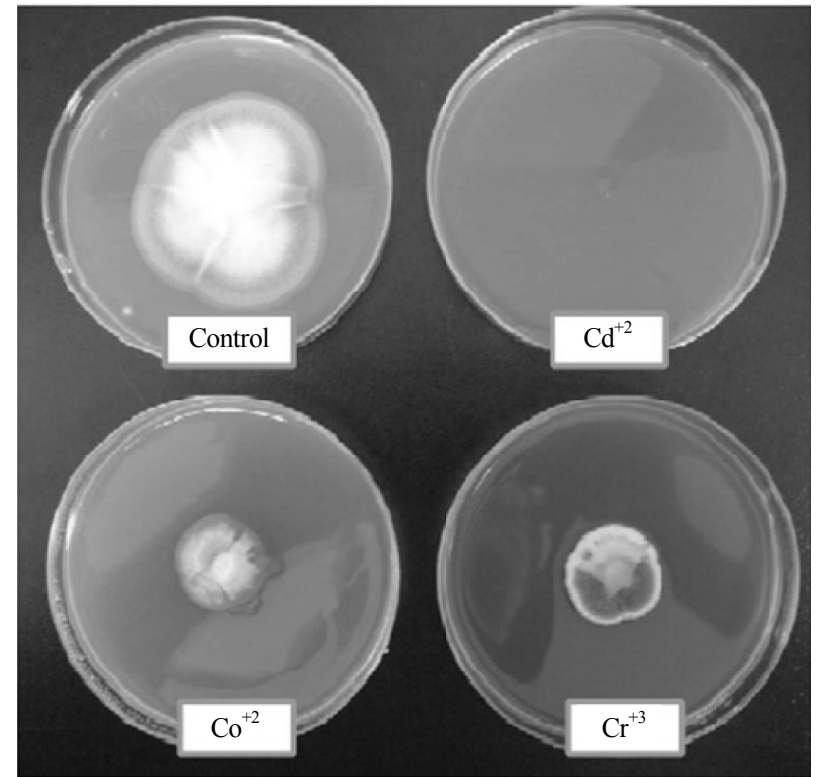

Fig. 5. The tolerance index of $1 \mathrm{mM}$ of different heavy metals on the growth of $P$. glabrum $\mathrm{KNU5} \mathrm{Cd}^{+2}, \mathrm{Co}^{+2}$, and $\mathrm{Cr}^{+3}$ decline the growth rate in comparing to control plate.

KNU3 (Table 4). The species showed more resistance to $\mathrm{Zn}^{2+}$ and $\mathrm{Pb}^{2+}$ which were the highest heavy metal concentration in the contaminated soil samples (Table 3). $1 \mathrm{mM} \mathrm{of} \mathrm{Pb}^{+2}$ increased the growth slightly of $P$. verrucosum KNU3 as a resistant fungal strains. This adaptation was suggested to refer to two factors (Almås et al., 2004). The first one is a gradual decrease in metal availability due to immobilization reactions. The other factor is a gradual change in microbial community structure, based on changes in phospholipid fatty acid profiles (Frostegård et al., 1993) which results in more tolerant organisms. The isolates showed sensitivity regarding the low concentrated heavy metals such as the $\mathrm{Ni}^{+2}$ and $\mathrm{Co}^{+2}$. Cadmium at concentration $1 \mathrm{mM}$ showed the strongest inhibition effect on the growth rate of the resistant fungal isolates, $1 \mathrm{mM}$ $\mathrm{Cd}^{+2}$ decreased the growth rate of $P$. verrucosum KNU3 extremely. Ezzouhri et al. (2009) reported similar findings. Addition of only $0.1-0.2 \mathrm{mM} \mathrm{Cd}$ led to severe inhibition of a Schizophyllum commune strain (Lilly et al., 1992). Our data indicated that tolerance of fungal species to heavy metals seems to be strain and origin dependent.

\section{Acknowledgement}

This study was supported by National Research Foundation of Korea Grant funded by the Korean government (Project number: 2010-0011988)

\section{References}

Abou-Shanab, R.A. I., P. van Berkum, and J.S. Angle. 2007. Heavy metal resistance and genotypic analysis of metal resistance genes in gram-positive and gram-negative bacteria present in Ni-rich serpentine soil and in the rhizosphere of Alyssum murale. Chemosphere, 68:360-367.

Alloway, B.J. 1995. Heavy metal in soils. Second edition, Chapman \& Hall, London.

Almås, Å.R., L.R. Bakken, and J. Mulder. 2004. Changes in tolerance of soil microbial communities in $\mathrm{Zn}$ and $\mathrm{Cd}$ contaminated soils. Soil Biol. Biochem., 36:805-813.

Baldrian, P. 2003. Interactions of heavy metals with white-rot fungi. Enzym. Microb. Technol. 32:78-91.

Balsalobre, L., M.I. De Siloniz, M.J. Valderrama, T. Benito, M.T. Larrea, and J. M. Peinado. 2003. Occurrence of yeasts in municipal wastes and their behavior in presence of cadmium copper and zinc. J. Basic Microbiol. 43:185-193.

Cánovas, D., C. Durán, N. Rodríguez, R. Amils, and V. Lorenzo. 2003. Testing the limits of biological tolerance to arsenic in a fungus isolated from the River Tinto. Environ. Microbiol. 5(2):133-138.

Chander, K, P.C. Brookes, and S.A. Harding. 1995. Microbial biomass dynamics following addition of metal-enriched sewage sludges to a sandy loam. Soil Biol. Biochem. 27:10491421.

Davis, R.R., W.J. Murphy, J.E. Snawder, C.A. Striley, Henderson, A. Khan, and E.F. Krieg. 2002. 'Susceptibility to the ototoxic properties of toluene is D., species specific', Hear. Res. 166 (1-2) 24-32.

Diels, L., N. Van der Lelie, and L. Bastiaens. 2002. New development in treatment of heavy metal contaminated soils. Rev. Environ. Sci. Biotechnol. 1:75-82.

Doelman, P., E. Jansen, M. Michels, and M. Van Til. 1994. Effects of heavy metals in soil on microbial diversity and activity as shown by the sensitivity-resistance index, an ecologically relevant parameters. Biological Fertilized Soil 17:177-184.

Domsch, K.H., W. Gams, and T. Anderson. 1980. Compendium of soil fungi Vols 1 and 2. Academic Press. London, pp. 405-859.

Durán, C., I. Marín, and R. Amils. 1999. Specific metal sequestering acidophilic fungi. In: Amils, R.; Ballester, A. (eds). Biohydrometallurgy and the Environment toward the Mining of the 21st Century. Elsevier, Amsterdam. 521-530.

Ezzouhri, L., E. Castro, M. Moya, F. Espinola, and K. Lairini. 2009 Heavy metal tolerance of filamentous fungi isolated from polluted sites in Tangier, Morocco. Afr. J. Microbiol. Res. 3:035-048.

Frostegård, Å., E. Bååth, and A.Tunlid. 1993. Shifts in the structure of soil microbial communities in limed forests as revealed by phospholipid fatty acid analysis. Soil Biol. Biochem. 25:723-730.

Gadd, G. M. 1993. Interaction of fungi with toxic metals. New Phytol. 124: 25-60.

Gavrilesca, M. 2004. Removal of heavy metals from the environ- 
ment by biosorption. Eng. Life Sci. 4(3):219-232.

Gupta, R., P. Ahuja, S. Khan, R.K. Saxena, and H. Mahapatra. 2000. Microbial Biosorbents: Meeting challenges of heavy metal pollution in aqueous solutions. Curr. Sci. 78:967- 973.

Hinojosa, M.B., J.A. Carreira, G.R. Roberto, and P.D. Richard. 2005. Microbial response to heavy metal-polluted soils: Community analysis from phospholipid-linked fatty acids and ester-linked fatty acids extracts. J. Environ. Qual. 34:1789-1800.

Holtan-Hartwig, L., P. Dörsch, and L.R. Bakken. 2002. Low temperature control of soil denitrifying communities. Soil Biol. Biochem. 34:1797-1806.

Itoh, S.M. Iwaki, N. Wakao, K. Yoshizu, A. Aoki, and K. Tazaki. 1998. Accumulation of $\mathrm{Fe}, \mathrm{Cr}$ and $\mathrm{Ni}$ metal inside cells of acidophilic bacterium Acidiphilium rubrum that produces Zn-containing. bacteriochlorophyll a. Plant Cell Physiol. 39(7):740-744, 1998.

Lee, I.S., O.K. Kim, Y.Y. Chang, B. Bae, H.H. Kim, and K.H. Baek. 2002. Heavy metal concentrations and enzyme activities in soil from a contaminated Korean shooting range. J. Biosci. Bioeng. 94(5):406-411.

Levinskaite, L. 2002. Response of soil fungi to chromium(VI). Ekologija. 1:10-13.

Leyval, C. and E.J Joner. 2001. Bioavailability of heavy metals in the mycorrhizosphere, In G.R. Gobran, W.W. Wenzel, E. Lombi (Eds.), Trace elements in the rhizosphere. CRC, Boca Raton, FL. pp. 165-185.

Lilly, W.W., G.J. Wallweber, and T.A. Lukefahr. 1992. Cadmium absorption and its effects on growth and mycelial morphology of the basidiomycete fungus, Schizophyllum commune.
Microbios. 72:227-237.

Mahapatra, N.R. and P.C. Banerjee. 1996. Extreme tolerance to cadmium and high resistance to copper, nickel and zinc in different Acidophilium strains. Lett. Appl. Microbiol. 23: 393-397.

Malik, A. 2004. Metal bioremediation through growing cells. Environ. Int. 30: 261-278.

Moubasher, A.H. 1993. Soil fungi in Qatar and other Arab countries. The Centre of Scientific and Applied Research, University of Qater, Doha, Qater.

Nakahara, M., Y. Suzuki, and R. Nakamura. 1978. Accumulation of cesium-137 by useful Mollusca. Bull. Jpn. Soc. scient. Fish. 44: 325-329.

Silóniz, M.E.M. Payo, M.A. Callejo, D. Marquina, and J.M. Peinado. 2002. Environmental adaptation factors of two yeasts isolated from the leachate of a uranium mineral heap. FEMS Microbiol. Lett. 210:233- 237.

Sumner, M.E. and W.P. Miller. 1996. Cation exchange capacity and exchange coefficients. p. 1201-1229. In D.L. Sparks (ed.) Methods of soil analysis. Part 3. SSSA Book Ser. 5. SSSA, Madison, WI.

Ray, S. and M.K. Ray. 2009. Bioremediation of heavy metal toxicity-with special reference to chromium. J. Med. Sci. 2: 57-63.

USEPA. 1994. SW-846 Method 3051, Microwave Assisted Acid Digestion of Sediments, Sludges, Soils, and Oils. Available online at http:/www.epa.gov/epaoswer/hazwaste/ test/3xxx.htm. 